\title{
Pharmacy \& Therapeutics Committees: A Mock Meeting at AMCP
}

Despite recent controversy over formularies, $P$ \& T committees are alive, well, and growing in influence and sophistication. In this article, highlights from a mock meeting are presented.
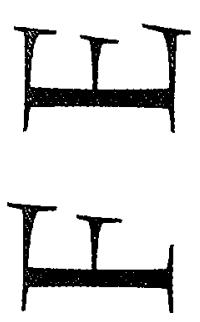

\section{KAREN SOUTHWICK}

\footnotetext{
KAREN SOUTHWICK is a San Francisco-based contributing writer for Pharmacare Economics, a supplement to Managed Healthcare.
}

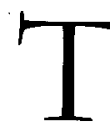
he "mock" P\&T committee meeting staged at the Eighth Annual Meeting of the Academy of Managed Care Pharmacy in San Francisco demonstrated the broad gamut of issues that pharmacists and other professionals must wrestle with today in deciding whether to approve a drug for inclusion on a formulary.

The workshop was moderated by Arlene McCollam Price, Pharm.D., director of drug policy and clinical outcomes for Prudential Pharmacy Services, Roseland, N.J. Other panelists included Leslie Fish, Pharm.D., with Fallon Clinic, Worcester, Mass.; Kimberly P. McDonough, Pharm.D., with ProMark, Providence, R.I.; Lydia Nesemann, Pharm.D., with PCS Health Systems Inc., Scottsdale, Ariz.; Bob Rase, Pharm.D., with Humana Health Care Plans, Kansas City, Mo.; and Yvonne Southwell, R.Ph., with Caremark Pre- 
scription Service Division, Chicago.

The panel "reviewed" six products recently approved by FDA: Precose (acarbose), indicated for management of noninsulin dependent diabetes; Zyrtec (ceterizine), a semisedating antihistamine; a group of three protease inhibitors, Invirase, Crixivan, and Norvir, for treatment of AIDS; Rilutek (riluzole), for treatment of amyotrophic lateral sclerosis (ALS); Androderm, transdermal testosterone; and Valtrex (valacyclovir), indicated for herpes zoster and genital herpes.

\section{FDA'S FAST TRACK MEANS A LACK OF INFORMATION}

Panel members complained of lack of outcomes and other data related to the protease inhibitors and Rilutek, all of which received fast-track approval by the Food and Drug Administration because of the catastrophic nature of the diseases they treat. "We have shifted some of the cost of doing research from the pharmaceutical companies and the $\mathrm{NIH}$ [National Institutes of Health] to private payers and public assistance programs," complained McDonough, who oversees the Tennessee Medicaid pharmacy benefit for ProMark.

For instance, she said, the protease inhibitors "are three products we don't know very much about," especially when it comes to interactions with legal or illegal drugs, or with methadone. "Over 50\% of my AIDS patients are drug abusers," she said. "Can we take the risk of interaction?"

In the past, Price noted, many P\&T committees approved drugs for AIDS patients as soon as they came out of FDA because of the nature of the illness. Also, she added, pressure from AIDS advocacy groups and the high profile of the disease made it difficult not to put products on formulary. But with the addition of the protease inhibitors, panelists agreed that knee-jerk approval was no longer warranted. "We need to lean heavily on the recommendations of knowledgeable physicians," said Fish. McDonough suggested credentialing AIDS centers to guarantee expertise

In the end, the panel voted unanimously to put the three protease inhibitors on formulary, but to limit prescribing to AIDS specialists who have undergone a credentialing process. They also voted for a mandatory followup and tracking program to see how patients do on the drug.

\section{LOU GEHRIG'S DISEASE: PHARMACOTHERAPEUTIC CONSIDERATIONS OR ETHICS?}

The discussion on Rilutek followed a similar pattern. Price informed the panel it was the first approved product for management of patients with ALS (Lou Gehrig's disease), a fatal neurogenerative disorder. At a cost of about $\$ 750$ a month, Rilutek showed a slight prolongation of life and avoidance of a ventilator-for an average of about 90 days.

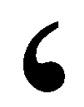

In the past, many PET committees approved drugs for AIDS patients as soon as they came out of FDA because of the nature of the illness.

\section{-Arlene McCollam Price<smiles>[CH][CH]</smiles>

Said Rase: "This is a very difficult product to evaluate from a $\mathrm{P} \& \mathrm{~T}$ perspective. We really need an ethicist to discuss this." The real dilemma is, if coverage is denied, "Do you want to make the decision to deny these patients hope?" he said. "Do you make this decision with your heart or your head?"

McDonough pointed to the plethora of products coming out that offer very small improvements for catastrophic illness. "Is it worth spending an enormous amount to give a small population a marginal benefit?" On the other hand, she said, for the same $\$ 750$ it takes to provide Rilutek to one patient for a month, "we can take care of the hypertension in a large population and have a huge impact. Do we disenroll 60,000 kids and moms [from Medicaid] to cover 2,500 people with a catastrophic illness?"

Price suggested that private payers could begin offering optimal health insurance riders to cover catastrophic illnesses, but few employers or employees are willing to pay the extra premium cost. McDonough added that if a health plan in one area decides to cover a catastrophic drug and no one else does, it is opening itself up to adverse selection: "We don't want to be the only ones getting all the extremely expensive patients."

In the end, the panel did agree that they could not deny coverage of Rilutek, and voted unanimously to put it on formulary. However, only neurologists would be allowed to prescribe it, and a quality-control committee would be directed to develop guidelines for identifying patients for whom the drug is appropriate.

\section{TESTADERM: A VERY SENSITIVE SUBJECT}

Discussion of Androderm was a bit more light-hearted. Approved for replacement therapy for testosterone deficiency, Androderm is delivered by means of a skin patch that can be placed anywhere on the body. By contrast, Testaderm, a competing product already on formulary, must be applied directly to the scrotum by means of an adhesive-and then only after the scrotum has been shaved.

Panel members looked naturally to Rase, the only man on the panel, to lead the discussion. "I definitely think we need to add [Androderm]," he recommended. "It's a good alternative" to existing products.

Price reminded panelists that Androderm is receiving considerable offlabel use as a treatment for AIDS wasting, even though no clinical data are available to support that view. She suggested any recommendation for inclu- 
sion on formulary include retrospective review to track whether the product is being used inappropriately.

Nesemann got to the essential point of whether Androderm should replace Testaderm on formulary: "It's really a placement issue," she said, to knowing giggles from the audience. "Which of these products is someone more likely to use?" At that point the panel voted unanimously to put Androderm on formulary in place of Testaderm, with retrospective review to assure appropriate prescribing.

\section{ANOTHER ANTIHISTAMINE: NOT NOW}

The other three products were either rejected for formulary inclusion or tabled. Zyrtec, the new antihistamine, received a few lukewarm arguments for inclusion based on the fact that manufacturer Pfizer Inc. has announced a lower price than competing non-sedating products such as Claritin or Hismanal. "Patients will ask us why we would restrict something they see as a lower-cost product," said Southwell. Rase said if Pfizer came in with a big discount for the product, he might consider listing it, but only on that basis.

But other panel members felt that the combination of prescription, nonsedating antihistamines, coupled with use of nonprescription sedating products at night, could keep a plan's cost just as low as using Zyrtec. "We already have too many antihistamines," said Fish. "What is working and not working? We don't know." She added that this is one area where most people are capable of self-medicating. "We should be pushing the OTC medications because patients' premiums will go down. We're also telling patients that they can take care of themselves." Fish added that Fallon Clinic at least had not seen a lot of requests from its physicians to prescribe Zyrtec.

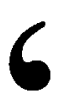

\section{We should be pushing the OTC medications because patients' premiums will go down.}

\section{-Leslie Fish}

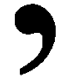

"What does semi-sedating really mean?" asked Nesemann. "It's not welldefined, and we already have plenty of antihistamines on formulary." The panelists unanimously rejected the product for inclusion at this time, but voted to re-evaluate it in six months.

\section{PRECOSE: NOT URGENTLY NEEDED}

Precose, the new diabetes drug, ran into similar arguments about its lack of demonstrable new benefit to the indicated population. It also has side effects that make patients reluctant to stay on it for very long. Price explained that those include extreme flatulence and loud bowel sounds that can last for months. "The product is not well tolerated, and that can be a major limitation," said Rase, in an understatement.

Fish pointed out that other products in the noninsulin category were also being introduced, making inclusion of Precose not very urgent. "There are other products in this category that appear to be more efficacious," added
Southwell. "We would prefer to wait on formulary inclusion until there is more evidence."

Panelists considered the possibility of restricting the product to prescription by diabetologists only, accompanied by guidelines for use, but in the end agreed to wait until other products emerge and data exists to choose between them. Precose was rejected by the panel 4-1, with Southwell casting the dissenting vote. "I would recommend allowing it to be covered until the other products come out," she said. Precose will also be re-evaluated in six months.

\section{VALTREX: TABLED WHILE AWAITING GENERIC ACYCLOVIR}

Finally, the panel decided to table Valtrex for future consideration when it could consider its usage versus a similar acyclovir-like product. Panelists agreed it made sense to keep acyclovir itself on formulary because a generic product is expected at the end of 1997 and physicians would remain accustomed to using it to allow for generic substitution next year. "There's no real value in having three of these agents on formulary," summed up Nesemann. "We need to reevaluate Valtrex versus Fanvir, and look at bidding those two against each other."

\section{FORMULARIES ALIVE \& WELL -}

As this healthy P \& T discussion demonstrates, selection of agents for inclusion on formularies is an effective method of reaching rational decisions in situations where reasonable people may differ. Managed care organizations continue to use preferred drug lists effectively in managing their drug benefits programs. 